\title{
LISTENING TO THE ARCHAIC IN THE ADULT
}

\author{
René Roussillon ${ }^{24}$
}

\begin{abstract}
Certain early experiences of a traumatic nature have not been subjected to the conventionally described processes of "après-coup" reorganization because of the defence mechanisms implemented against the traumatic threat they harbour. Using vignettes from different sessions, I study the process by which these early experiences merge with transference during treatment, thus offering the opportunity for a first form of après-coup and therefore becoming secondarily elaborable. This occurs provided that the analyst is sensitive to the non-verbal forms of returning archaic experiences. I will then describe the nonverbal forms of returning archaic experiences using various clinical examples.
\end{abstract}

Keywords: Après-coup, procedural and declarative memories, synthesis and integration, archaic, primary traumas, language of the affect.

\section{Introduction: the question of the après-coup}

During an evening of our doctoral student seminar, I presented the model I was beginning to obtain concerning the forms of "solutions" put in place by subjects who had experienced primary trauma. ${ }^{25}$ I started from the psychoanalytic clinic cases of adult subjects and the "reconstruction" work that this made possible. I imagined what could have happened in their early years which could lead to current clinical manifestations. One of the participants drew my attention to a work by

\footnotetext{
${ }^{24}$ The Paris Psychoanalytical Society; rroussillon7@gmail.com

${ }^{25}$ The model I refer to is the one I present in the first chapter of my 1999 work, Agonie, clivage et symbolisation, PUF
} 
S. Fraiberg concerning the first defence mechanisms of babies faced with great psychic danger, something she'd observed in Michigan (Fraiberg, 1993, pp.7-29). The superimposition of my reconstructions resulted from the adult clinical cases and the direct clinical observations of S. Fraiberg deeply impressed me and convinced me to take an even greater interest in infancy clinical cases and, especially, to closely reconsider the "classic" positions according to which the past, reinterpreted in après-coup throughout history, was hardly knowable.

The fact was indeed quite disturbing and invited two types of hypotheses.

On the one hand, from the adult cures' clinical material, one could envision reconstructing a fairly faithful representation of the processes at work in babies. On the other hand, we could "observe" in the cases of babies psychic mechanisms that adult psychoanalysis highlights. Because interest must be generated in both directions.

Such hypotheses called into question the "dogma" that prevails in certain psychoanalytic circles and according to which psychoanalysis has nothing to learn from the treatment or the observation of babies or young children, that there is no overlapping of fields. However, they also invite us to again take up the question of the après-coup process, so essential in psychoanalytic treatment, according to which what we observe in the treatment of adults concerns a history so altered that we cannot base ourselves on what we observe and understand in adults to infer anything about early childhood. In passing, we underline that this position was not that of Freud, who thought that one could go back to the events of early childhood through analysis. We will return to his position later.

There may have been a shift in recent years regarding the aprèscoup, which resulted in it becoming a theoretical war machine against the work of historicization. 
According to Freud, the après-coup mechanism relates to meaning, not to fact. It is not history itself that is altered, but, fortunately, the meaning of events. This is, it should be noted in passing, even if the argument cannot be conclusive, congruent with what neurosciences have observed for their part (I am thinking of the work of Nobel Prize winner E. Kandel, for example).

On the other hand, if the "après-coup » reinterpretation mechanism is truly a fundamental process and an achievement of psychoanalysis and clinical thought, it does not apply to all that has happened in the past. It is clear that the more a subjective experience has been integrated, symbolised, historized, the more it merges into the weaving of the ego and the less it remains present as such, the more it becomes reworked and reinterpreted. However, the less it is integrated, the more it retains a traumatic impact; the less it has been symbollised, the more it tends to retain the perceptual forms of the time of its recording, the more it tends to reproduce itself as is.

Freud emphasizes, moreover, in this regard two points which are essential here.

On one hand, in 1915 in the article on metapsychology devoted to repression, Freud underlines that previous experiences are those that tend to give meaning to later experiences. If they are repressed, they "attract" to themselves analogous later experiences. This is the very process of "transference" psychoanalytic practice is based on. The current situation is interpreted unconsciously, infantile experiences that thus seek to be recognised.

However, in 1938, so towards the end of his work, Freud goes even further, underlining that "early experiences, contrary to what happens later, are all preserved" and then proposing the following explanation - "weakness of synthesis, the conservation of the character of primary processes" (Freud, 1938, p. 287). 
Here again, in my opinion, Freud's position seems to be largely convergent with current achievements of biology that underline the existence of "procedural" forms of memory, which constitute schemas of interpretations for later experiences. To me the "internal working model" described by Bowlby seems to be of the same type.

Early and infantile experiences establish prototypes, models of interpretation, of recording and of making sense, which will help orient the subsequent subjective experience and its significance. Even when there is an après-coup reinterpretation and rearrangement of early experiences, the latter leave traces, especially in the way later experiences are organized, but also in other types of signs, as we will see further on.

\section{Listening to the archaic in the adult}

If the preceding arguments sufficiently reopen the question of listening to the traces of early experiences in the psychic functioning of the adult, so that they continue to be examined clinically, then a first question arises: what signs or what types of signs could these experiences leave? How to listen to "the baby" in the adult? How do traces of early experiences manifest themselves in the psychic life of children, adolescents or adults?

There are surely no clinical signs that testify by themselves to the presence of substantial traces of early experiences in the background of psychic functioning. Usually the specialist relies instead on a fascicle of facts, able to derive their convergence and intelligibility from a hypothesis concerning an early experience underlying these clinical facts. Of course, a psychoanalyst always begins by first seeking the answers to the clinical questions he asks himself from the transference manifestations within the analytic situation. The transference is the main guide of clinical thinking. Listening to the nature and type of 
transference is the primary tool in the psychoanalytic exploration of a question.

As to what concerns us, we can move forward quickly, as I do not wish to focus on how we have a first potential trace of early states when transferential dependence or the active fight against it is very important, insofar as they occurred in a state of manifest objective dependence. This gives a first form of the context in which the question of early experiences arises. The presence of the process of idealisation or, conversely, that of counter-idealization, also seems to indicate a relational mode referring to early experiences. The forms of destructiveness are still indicators to be taken into account. Early instinctual life has certain characteristics that "mark" a specific relational style; for example adhesiveness is relatively typical. All of this is classic enough that I won't insist any further.

I content myself with evoking a brief clinical sequence that, in my opinion, seems illustrative of this mode of presence of early experiences. L is a woman who suffers from the threat of "panic attacks". She is engaged in an active defence against her transferential dependence, which nevertheless seems to me very sensitive to various clinical characteristics, even if it is not recognized. Upon returning from summer vacation, she felt like she was knocking at my door, which she felt was closed. In the session, she recalls a moment of intense anguish that had emerged during her vacation, while on a boat cruise.

The waterfront was all crowded and there was no way to dock. That's when the anguish set in. Of course I think about her fantasy of my closed door. She fears that I too will be "blocked", closed to her. While on vacation, she 'treated' with this panic by engaging in frenzied sexual activity with her husband. The sessions that followed were "intense", leading me to give some credit to the hypothesis of the repetition of early experiences of encountering a mother who is, most of the time, caught up in her own narcissistic issues and relatively 
"blocked off" from her daughter, insensitive to her distress. Feedings were the only moments when it seemed that communication with the mother could have been experienced as relatively satisfactory. $L$ then revealed herself to be relatively bulimic, which will not surprise any clinician. It manifested until adolescence, when she transferred it into a form of "sexual bulimia" whose function seemed to be equivalent, even if the form was different. A beautiful woman, L easily found partners who were ready to satisfy her appetites, even though she suffered from this form of duress at the same time.

In transference, $\mathrm{L}$ repeats these first characteristics in a transformed form. She seems not to suffer from withdrawal between sessions, but every time one of them is cancelled or she herself is absent, and at the time of the session that was initially scheduled, something happens (a burst of anxiety, for example), which can generally be significantly linked to not having a session. However, sessions are always quite intense and engaged, probably following the model of the first feedings that concentrated most of the moments of encounter and communication. For a while L eroticised the sessions, and the question of a potentially heavily sexualised transference was always present during them.

We thus find the "solution" that she was able to provide secondarily through sexualisation to ease her primary anxieties. But this "solution" takes place on the initial model of intense breastfeeding encounters with her mother, "transferred" into the realm of sexual behaviour. The early relationship and its data are not directly present as such, yet they leave many traces in the patient's current organisation. They organise a "model" that we will find displaced and transformed in other aspects of his psychic life. This leads us to what Joyce McDougall called "primitive communication".

It seems to me that an important step was taken in locating the communication of early experiences when we began to consider that 
certain forms of affect, action, or bodily or somatic manifestations were not only modes of drive "discharge", which sought to remove psychic content from representation and language, were not only defence mechanisms, but also attempts to take into account and listen to old modes of communication and experiences, from before the appearance of language. We can then switch from a "negative" mode of listening to these different psychic formations to a more "understanding" listening to their meaning.

This the foundation for this passage that I would like to further develop now.

One of the characteristics of the "baby within the adult" is that early subjective experiences were undergone before the onset of verbal language. One of the hypotheses that may be of some interest is that they have been recorded in forms which precede the forms of language representations, leaving pre-verbal traces that will tend to be reactivated in the transfer in forms that do not fit into forms of linguistic communication - that they will produce preverbal signs.

We are going to examine what forms they can then take, but we must first focus on this hypothesis.

Our early experiences are undoubtedly originally "recorded" in the form they took in the time they were experienced. However, it seems quite clear that some of these were then secondarily linked to later experiences and that they could thus be secondarily re-inscribed and represented in verbal forms. We can therefore think that a part of our early experiences was thus integrated into our system of verbal representations, that it was "transferred" into the language apparatus. The impact of this part of early experiences then enacts its influence on the language forms themselves, its components. It manifests itself through certain non-verbal aspects of verbal language, prosody for example, melody, tone, duration, rhythm of words and sentences. 
I previously studied in La rhétorique de l'influence [The rhetoric of influence] and La matérialité du mot [The materiality of the word] (Roussillon, 1999) how we could find traces of early bodily experiences or preverbal psychic states in the style, the form of the utterance. In fact, verbal language does not transmit only reflected forms of psychic representation. It also contains a mode of action, a mode of influence which acts on the other and communicates to him, beyond the contents of the words themselves, experiences of being. The representations of things, the representations of action and the first modes of the signifier are transferred into the language apparatus.

Additionally, sometimes this work of recovery fails because the early experiences were separated from the first subjective experience, and therefore unable to be recorded again in language. The traces of these experiences are "encysted" in primary narcissism. They are split from integrative processes and therefore retain a form that is hardly subject to après-coups.

This clinical hypothesis is similar to that proposed by Winnicott in his article La crainte de l'effondrement [Fear of breakdown] (Winnicott, 1974) in which he hypothesizes that certain early nonsubjectivized traumatic experiences continue to threaten the psyche. $\mathrm{H}$. Faimberg (Faimberg, 1998), reflecting on these clinical circumstances, emphasizes that the first après-coup of these early experiences takes place in the treatment, when the defences opposing their psychic integration have begun to be sufficiently worked through.

My personal clinical experience points in the same direction, I think that certain early states, against the return of which the psyche has actively organized, will tend to return during analysis and manifest themselves with the help of primitive modes of communication, that is to say modes preceding the emergence of verbal language. 
Therefore a reflection on the way in which "the baby within the adult" manifests itself, to keep this convenient metaphor, leads us to look at the primitive and preverbal modes of communication.

It is likely that the first "language" utilised by young children is the language of affect, but it is no less probable that the language of affect in the baby is not exactly the same as what will develop later, when emotional life is itself related to verbal language. However, affect, as C. Darwin first pointed out, contains a message that concerns the subject itself while also addressing the other. It even seems more than likely that he first seeks to communicate a psychic state to the other before the baby even communicates it to himself, being "experienced" by his affects more than really reflecting on them.

Clinical practice teaches us that there is a quality of affect without words, of affect "before" words, very different from affect inserted into language. This is why in the treatment it is so important that the internal states be enabled to find a way to relate to the representations of words, the latter domesticating their effects. All those who use analysis in working with narcissistic-identity issues know these wordless states of distress that are expressed only through the affective manifestations themselves.

States of stupor, terror, certain forms of fury or rage which appear rather as primitive "traumatic disturbances of the entire being", which Freud states in 1926 as being simple signal-affects, rather than later affects. Therefore, the "passional" character of certain affects also seems to be an indicator of the presence of an archaic component. I was able to hypothesize that the passionate form of affect resulted from the amalgamation of an archaic experience and a sexualization originating in adolescence.

Yet the affect is also the sensation, the intra-bodily sensation in particular. Here is a quick clinical sequence to illustrate this topic. 
Marine is a young woman whose analysis has progressed well for several years, in particular towards the exploration of the sadomasochistic characteristics of her relationship with men and the prototype of these men, linked to her father. For some time now, it is the relationship with her mother that has taken centre-stage in the analytic scene. Marine has suffered from numerous bouts of "heartburn" for many years. At first these diminished during analysis, but since the relationship with her mother emerged at the centre of her concerns, they have picked up again. One day Marine arrived for her session and told me that, in the waiting room, she started to feel very unwell, she is on the sofa, in pain, but she does not say where this pain is, yet her hand rests on her stomach area. The session continues and it becomes clear that it could not carry on as such for long, so long as Marine seemed unwell. I am very preoccupied with this pain, especially since it started in my waiting room and so seems directed to me. I feel I need to intervene so I end up saying to her, "When you were a baby, the bottles your mother gave you were too hot, they burned you". I mentioned a bottle because it is clear that the breast can never burn. Marine is silent for a moment before replying - "I don't know, but when you said that I thought about how my mother always serves hot coffee, and always wants us to drink it while it is very hot". Just as Marine says these words, her heartburn goes away.

The sessions that followed were dedicated to working through her mother's "burning" aspects, and Marine's father's difficulty in "cooling" the mother. Bit by bit, the burning sensation gave way to the elaboration of a metaphorical motherly "warmth".

Here, everything seems to happen as if the bodily sensation, which Marine can hardly name and that she shows me with her hand, comes to "meddle" in the conversation and to register within the maternal transference, representing an early fragment of the 
relationship with the mother, which bears the trace of painful states from early childhood.

We perceive what the hypothesis of a primitive communication taking place on the basis of affects or bodily states brings. It allows us to avoid getting bogged down in an analysis (that often takes the value of denouncing) of the defensive aspects of perception or sensation, and conversely it opens the analysis in the direction of a reconstruction of the primitive modalities of relation.

These hypotheses to me seem very important in what concerns the psychosomatic affections that are manifested by bodily sensations. I hypothesised that one of the starting points for these could be found in intracorporeal coenesthetic hallucinations of sensations, witnesses of primitive states and possibly relating to a primitive mode of communication. We know very well how babies "express" with their bodies certain bodily diseases as well as states of discomfort.

Face to face, "primitive communication" presents other types of corporal manifestations. For example Chloé, as soon as it is my turn to speak, covers her mouth with her hand, palm turned towards me as if to form a "barrier" that would prevent my words from "entering", but as soon as what I say agrees with her, she puts her hand down. This happens as if my words "enter" through the mouth or could be halted there.

Mimicry, gestures and posture tend to communicate what cannot be said, what could not be uttered, oftentimes because language was not yet there so expression had to take place some other way.

I have previously proposed the hypothesis that what we call negative therapeutic reaction, which consists of a worsening of the clinical scene of the analysand during the treatment, could also be understood as a manner of saying no, there where the concept of "no" is not yet available. Of course the negative therapeutic reaction is not only that, but it could also be that. In 1925 when Freud focuses on 
"negation", he clearly evoked the hypothesis of bodily "prototypes" of negation and affirmation: "I should like to eat it or spit it out" would be a primitive bodily expression (Freud, 1925). Before the emergence of language, the body is in charge of expressing what words cannot yet say. It is the body that becomes the messenger of states of being. The body through its affects, its facial expressions, its gestures, its postures and also its motor skills and actions, deploys a form of primitive language. Moreover, it does not utilise this means of communication just in early states. Bodily expression remains present alongside verbal language, even when the latter has developed, but it is likely that the presence of verbal language modifies both the form of bodily expression and the mode of presence of bodily communications.

There is still a register of primitive communication that we have only scratched the surface of - that of the act. The act has a bad reputation when it comes to clinicians listening. It is often seen as a defensive manifestation which seeks to avoid the work of symbolization that the psyche faces. However, clinical treatment focusing on adolescence, on anti-sociality or on psychotic states, or even that of suicidal states, to me seems to indicate that we cannot reduce the act to this dimension alone. In a previous work (Roussillon, 1983) I tried to show how the act could conceal much greater complexities and potentialities and that it could not be reduced to solely the function of discharge. The act can also be used as a primitive means of communication. It can try to make what the subject cannot say to be felt instead, to bring to life or to "show" experiences that escape or precede the appearance of language. Of course, the act often involves a process of evacuation, of externalization. However, underlining its value as "messenger" allows it to be understood as a mode of expression of internal states that escape the language register. As I mentioned children, who cannot yet say "no" and shake their head instead, or even throw objects, bend backwards, vomit. They avoid the unpleasant 
situation by all possible means. When they cannot avoid it, they "evacuate" it.

I would like to end this quick introduction on listening to the "baby within the adult" and on the consideration of primitive communication with a final remark.

\section{Conclusion}

Conceiving the various clinical manifestations that I have just mentioned as modes of communication of archaic states, does not mean that they should be regarded only as such. My hypothesis does not cancel out the more classical interpretations. Instead it aims to dialectize itself to these classical interpretations, to provide additional recognition of the psychic complexity at work in psychic formations. Any communication from an adult must be able to be heard at different levels. The different organizational methods of the adult's personality contribute to each of the psychic formations that are expressed in treatment. This means that, when a formation of psychic life becomes significant in the transference, it necessarily includes a component resulting from adult sexuality and the impact of adolescence on it, as well as a component from infantile sexuality. In my opinion it is important to add the hypothesis that it also includes a dimension stemming from the early states of subjectivation, originating from the baby's experiences and specific modes of communication. This hypothesis often allows us not to be caught in an interpretation that is strictly negative. It opens the possibility of a more "benevolent" listening, that of primitive experiences which seek to be recognised as much as they seek to remain unrecognised. It does not limit listening within a hypothesis in the name of which only the destructiveness of the subject is expressed, only the subject's wish to evacuate a part of his psychic life. It opens a path to the idea of a message, i.e. a qualitative 
and not just quantitative value of expression. It opens up the way to a possible form of play. If the act and the actualization include an "acted message" from the subject, then it becomes possible to understand that this modality of act includes and conceals the potential of "primitive communication" games.

\section{REFERENCES}

FRAIBERG, S. (1993). Mécanismes de défenses pathologiques au cours de la première enfance, Devenir, 5: 7-29.

ROUSSILLON, R. (1999). Agonie, Clivage et Symbolisation [Primitive Agony and symbolization], Paris, PUF.

ROUSSILLON, R. (1983). Pensées sur l'acte [Thoughts on the act], in $\mathrm{R}$ Roussillon (1991), Paradoxes et situations limites de la psychanalyse [Paradoxes and borderline situations in psychoanalysis]. Paris, PUF. 